\title{
Long Term Arm and Shoulder Toxicities in Breast Cancer Patients Receiving Hypofractionated Radiation Therapy
}

\author{
Prateek Daga, Harvinder Singh Kumar, Neeti Sharma, Shankar Lal Jakhar, \\ Kamlesh Kumar Harsh
}

Department of Radiation Oncology, ATRCTRI, Bikaner, India.

\begin{abstract}
Aim: The purpose of this study is to evaluate the late toxicities in hypo fractionated radiation schedule in breast cancer patients with regional nodal irradiation (RNI), limited to axilla and supraclavicular regions. Late effects on arm and shoulder were noted as follows: skin edema (lymphedema), restricted shoulder movements (brachial plexus injury) and localised pain. Material and Methods: In this study we randomly enrolled 100 breast cancer post mastectomy cases in the year 2018. All cases were previously asymptomatic after surgery. They were prospectively treated with hypo fractionated local and regional nodal irradiation by 2.67 gray / fraction dose, total 15 fractions (total dose-40 gray). Evaluation was done at 12 months after completion of radiation therapy. Assessment was done by RTOG, LENT- SOMA scales. Results: Significant lymphedema was observed in 17 (17\%) cases. Restricted arm mobility was seen in 14 (14\%) of patients. Pain (moderate/severe) in arm and shoulder was most commonly seen, in 25 (25\%) cases. Conclusions: As hypo fractionated regimes in breast cancer treatment have become new standard; its late term effects are significant and comparable to other conventional radiation therapy regimes. These studies need further and longer duration of evaluation.
\end{abstract}

Keywords: Breast Cancer- Radiation therapy- Hypo fractionation- Toxicities

Asian Pac J Cancer Care, 6 (3), 311-315

\section{Introduction}

Breast cancer is the most common female malignancy in the world, affecting more than 2 million people worldwide every year. A multimodality approach for its management is almost always required with patients undergoing a combination of radiotherapy, chemotherapy and surgery. Radiation therapy is the cornerstone of breast cancer care for definitive treatment approaches. As per existing standard guidelines in post axillary dissection, node positive breast cancer patients are given radiotherapy to lymph nodal area. This is done to improve loco regional control and survival [1-4]. Hypo fractionated radiation schedule has been proven safe and effective for tumour control with added advantage of less treatment time, supported by American Society For Radiation Oncology (ASTRO) group [5-7]. The concern with this dose schedule is a potential increase in acute and late term toxicities [8]. Late toxicities in breast and axilla irradiation are effects on heart, lungs, axilla (lymphedema), brachial
Submission Date: 02/02/2021 Acceptance Date: 07/15/2021

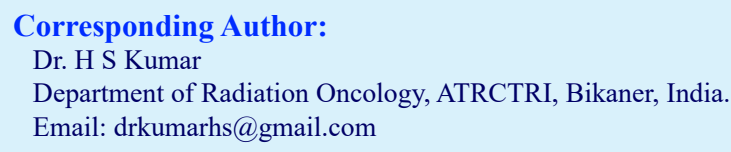

plexus, and general cosmesis.

\section{Materials and Methods}

From January 2018 - January 2019- 100 breast cancer patients were treated with mastectomy, axillary node dissection (AND) and loco-regional hypo fractionated RT (2.67 Gy per Fraction, in 15 fractions -Total dose 40 Gy) which is in agreement with several randomized trials which have shown to improve local control with mild side effects and acceptable cosmetic outcome [5]. The median age at diagnosis was 60 years (range 40-81). Histology in all patients was ductal carcinoma. Axillary lymph nodes metastasis was confirmed in all women. All patients received systemic chemotherapy either neo adjuvant or adjuvant with schedule of adriamycin and cyclophosphamide. All the patients were assessed priorly to rule out any post-operative complications that 
might mimic late toxicities. Follow up of patients was done at 12 months post completion of radiation therapy. LENT- SOMA scale were used to assess lymphedema (0-IV), pain severity (I-IV). RTOG Late toxicity assessment was done for arm stiffness $(0-\mathrm{V})$.

\section{Results}

Age distribution (in years) of the patient in study was 40-49-(17\%), 50-59 - (32\%), 60-69- (41\%), 70$79-(8 \%), 80-89-(2 \%)$ (Table 1$)$. In 17 patients $(17 \%)$ lymphedema was recorded during follow up: LENT SOMA grading was as follows; grade I-11, grade II- 5 and grade III -1 patient (Figure 1). In 12 (12\%) of patients symptoms started before radiation therapy and can most likely be attributed to surgery and systemic therapy. 5 $(5 \%)$ patients developed lymphedema which was likely radiation induced. The time of onset of lymphedema in the latter 5 cases was very variable (from 1 to 11 months from the end of radiotherapy). In 4 patients (grade I-2, grade II- 2) it was as a result of disease progression to the lymph nodes. Most common complaint was of pain seen in 25 patients $(25 \%)$. Severity (LENT SOMA) was-Grade I- 12 (12\%), grade II - 9 (9\%), grade III- 4 (4\%), and grade IV-0 (0\%) (Figure 2). Frequent complaint was pain aggravation upon arm movement/exercise, and relieved by rest and analgesics if patients was not able to tolerate it. Arm stiffness was present in $14(14 \%)$, grade I- 9 $(9 \%)$, grade $2-4(4 \%)$, grade 3- 1 (1\%) (Figure 3). Major difficulty faced by patients was restricted abduction of arm. Age group of patients with most symptoms of late toxicities was in 60-69 years of age.

\section{Discussion}

Hypo fractionated radiotherapy in breast cancer has become a common approach to manage breast cancer. This study investigated the late effects in patients who received this regime to chest wall and nodal regions. Clinical results achieved were similar to those achieved by standard regimens.
As reported in the literature, the irradiation of the lymph node area may increase the risk of side effects such as lymphedema and brachial plexopathy. Lymphedema may represent a standard complication after any axillary surgery. It is difficult to record as no clear parameter to measure lymphedema exists. Also it can be due to many contributing factors such as obesity, chemotherapy, extent of surgery [9-13]. Shah et al., provided the incidence of lymphedema according to the extent of RT after dissection, reporting a rate from 2-35\% after breast irradiation and an increased incidence to 9-65 $\%$ in the case of loco-regional irradiation [14]. In this study we used LENT SOMA questionnaire estimate clinical extent of the effects.

Shorter schedule has advantages of being safe, with good outcomes and better cosmesis compared to the standard radiation as it has been studied in several trials $[6,15]$. A recent update of START A and START $\mathrm{B}$ evaluated the loco-regional RT in a limited group of patients and neither the 5 week nor the 3 week treatment developed significantly worse normal tissue impacts: the assessments of arm and shoulder effects showed no evidence of a detrimental effect for the hypo fractionated schedules [6].

Yarnolds et al. observed no radiation induced brachial plexus toxicity after hypo fractionated irradiation of the axilla and/or supraclavicular fossa. It was stated that the START B regimen (40 Gy in 15 fractions/3 weeks) is equivalent to $47 \mathrm{~Gy}$ in $2.0-\mathrm{Gy}$ fractions if the $\alpha / \beta$ value for brachial plexus is $2.0 \mathrm{~Gy}$ or to $49 \mathrm{~Gy}$ in $2.0-\mathrm{Gy}$ fractions, if $\alpha / \beta=1.0$ Gy [15]. Haffty and Buchholz

Table 1. Age Distribution of Patients Enrolled in Study

\begin{tabular}{lc}
\hline Age (in Years) & Number of Patients \\
\hline $40-49$ & 17 \\
$50-59$ & 32 \\
$60-69$ & 41 \\
$70-79$ & 8 \\
$80-89$ & 2 \\
\hline
\end{tabular}

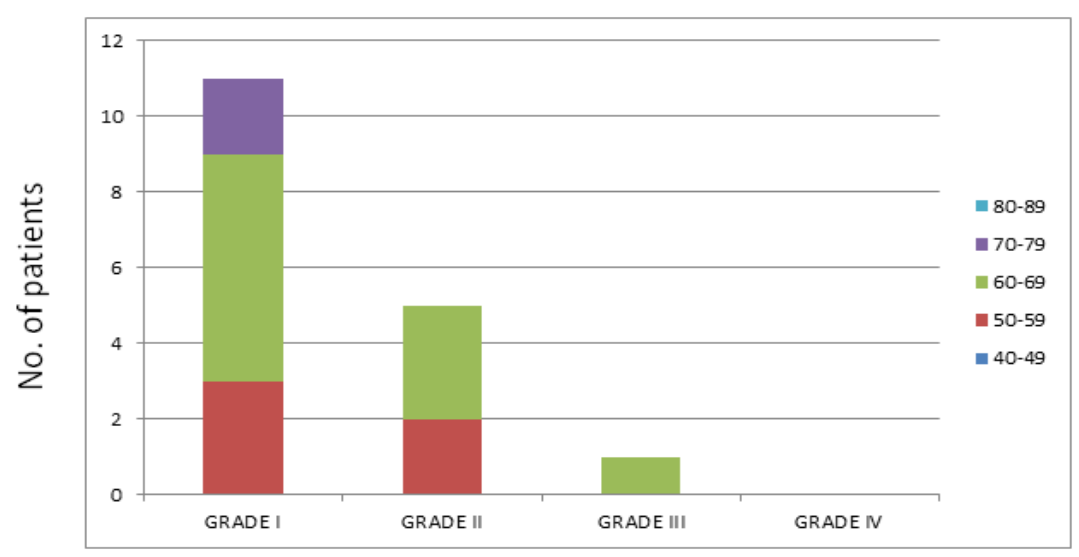

Severitv of Lvmphedema

Figure 1. Graphical Representation of Patients with Lymphedema 


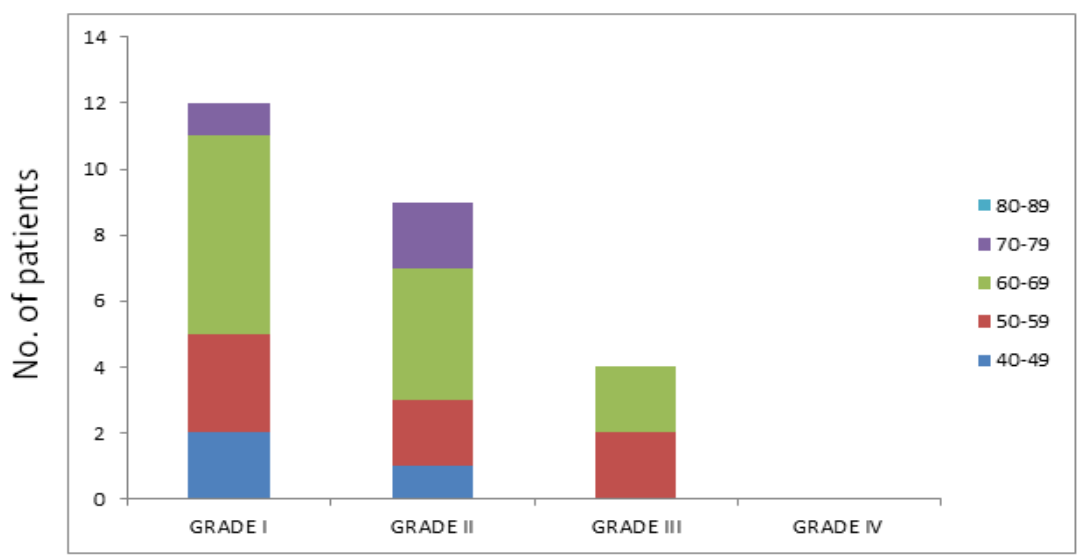

Severity of pain

Figure 2. Graphical Representation of Patients with Localised Pain

commented on the absence of side effects in the small group of patients (116pts of 2215, $7 \%$ ) enrolled in the START B trial and receiving regional hypo fractionated RT: they confirmed that these results are consistent with modelling of normal tissue effects, which predicts that 40 Gy in 15 fractions should be as safe as the standard scheme for all normal tissues [16]. Badiyan N. et al. noted that RNI with standard fractionation is associated with increased toxicity compared to WBI alone but current data do not support this observation [14]. The outcomes of our investigation seem to confirm what emerges from the literature: patients treated with hypo fractionated RT (40Gy in 15 fractions with 5 times a week) to the whole breast and infra-supraclavicular fossa did not show a higher rate of side effects, in 5 patients the lymphedema was radiotherapy induced, of which only 1 was severe. The favourable results obtained with this fractionation can be the basis for investigating new radiation schemes with a smaller number of fractions administered in reduced times.

Another concern of hypo fractionation in RNI is toxicity to brachial plexus. Patients can suffer pain, impaired arm movement, paraesthesia and in general poor quality of life due to this. As it depends on total dose, volume of irradiation and dose per fraction, assuming low $\mathrm{a} / \mathrm{b}$ ratios of 1.0-2.0 for the brachial plexus, hypo fractionated treatment regimens such as 40 Gy in 15 fractions would deliver a lower EQD2 to the brachial plexus than 50 Gy in 25 fractions [17] which significantly increases the risk of late toxicity. Standard RNI has rate of brachial plexopathy of $5 \%$ and paraesthesia in $20 \%[18-21]$ but START B found no such case in the study $[6,22]$. A retrospective review examining hypo fractionated PMRT with a subset receiving hypo fractionated RNI found no increase in rates of brachial plexopathy [23].

Delanian et al. evaluated the risk of plexopathy with hypo fractionated RNI schedules; incidence being more than $50 \%$ in $>4 \mathrm{~Gy} /$ fraction, though these studies used outdated techniques. These techniques have been found to have high rates of late effects in a retrospective data review done in Sweden $[27,28]$. It is observed that brachial

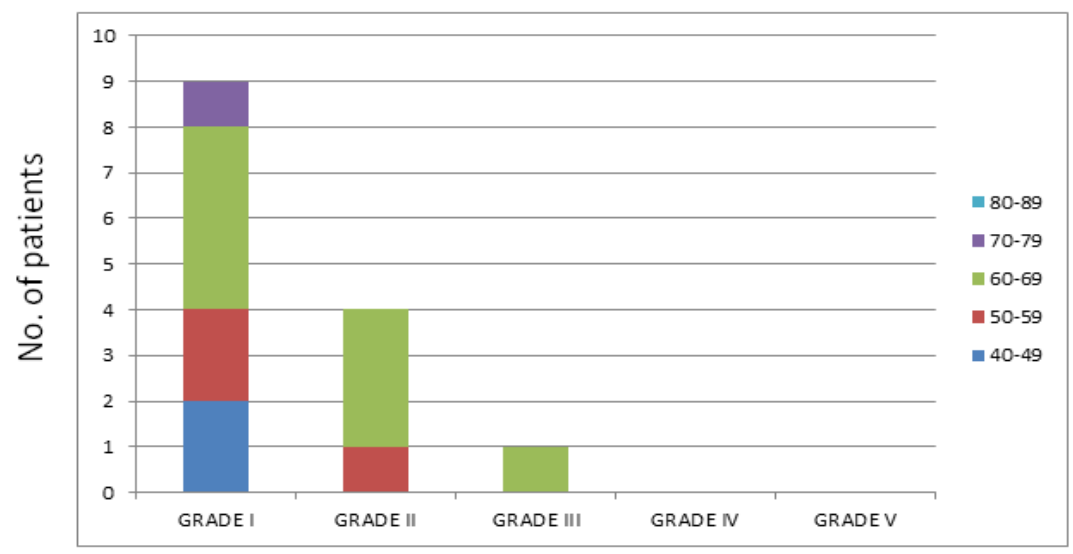

Severity of arm stiffness

Figure 3. Graphical Representation of Patients with Arm Stiffness 
plexopathy has been found to be less than $5 \%$ in doses per fraction below 3 Gy [24-26]. Major difficulty faced to record plexopathy is longer follow up requirement as major effects may occur beyond 5 years [29].

In conclusion, this study examined hypo fractionated RNI in accordance with previous published literature and evaluates long term toxicities at irradiated sites. These effects were found to be tolerable and mild. But, further review and longer follow ups are required for better understanding of effects at various organ sites; this is also supported by published data.

Demonstrating its safety and efficacy will allow more women to complete adjuvant radiation in shortened treatment duration. Further, from a healthcare economics standpoint, shortened schedules reduces the costs to the healthcare system and allows for increased availability of and improved access to expensive radiation therapy delivery platforms.

\section{References}

1. EBCTCG (Early Breast Cancer Trialists' Collaborative Group). Effect of radiotherapy after mastectomy and axillary surgery on 10-year recurrence and 20-year breast cancer mortality: meta-analysis of individual patient data for 8135 women in 22 randomised trials. The Lancet. 2014 06;383(9935):2127-2135. https:// doi.org/10.1016/s0140-6736(14)60488-8

2. AIRO 2013: Radiotherapy breast cancer: Indications and guidelines http://www.radioterapiaitalia.it/ allegato_1222_796.phtml.

3. NCCN. Clinical Practice Guidelines in Oncology ${ }^{\mathrm{TM}}$. Breast Cancer. http://www.nccn.org/professionals/ physician_gls/f_guidelines.asp\#breast. 2015;Version 1 .

4. Sautter-Bihl M, Sedlmayer F, Budach W, Dunst J, Feyer P, Fietkau R, Fussl C, Haase W, Harms W, Piroth M, Souchon R, Wenz F, Sauer R, of the of BCEPGS. DEGRO practical guidelines: radiotherapy of breast cancer III-radiotherapy of the lymphatic pathways. Strahlentherapie und Onkologie. 201403 05;190(4):342-351. https://doi.org/10.1007/s00066013-0543-7

5. Whelan TJ, Pignol J, Levine MN, Julian JA, MacKenzie R, Parpia S, Shelley W, Grimard L, Bowen J, Lukka H, Perera F, Fyles A, Schneider K, Gulavita S, Freeman C. Long-Term Results of Hypofractionated Radiation Therapy for Breast Cancer. New England Journal of Medicine. 201002 11;362(6):513-520. https://doi. org/10.1056/nejmoa0906260

6. Haviland JS, Owen JR, Dewar JA, Agrawal RK, Barrett J, Barrett-Lee PJ, Dobbs HJ, Hopwood P, Lawton PA, Magee BJ, Mills J, Simmons S, Sydenham MA, Venables K, Bliss JM, Yarnold JR. The UK Standardisation of Breast Radiotherapy (START) trials of radiotherapy hypofractionation for treatment of early breast cancer: 10-year follow-up results of two randomised controlled trials. The Lancet Oncology. 2013 Oct;14(11):1086-1094. https://doi.org/10.1016/ s1470-2045(13)70386-3
7. Smith BD, Bentzen SM, Correa CR, Hahn CA, Hardenbergh PH, Ibbott GS, McCormick B, McQueen JR, Pierce LJ, Powell SN, Recht A, Taghian AG, Vicini FA, White JR, Haffty BG. Fractionation for Whole Breast Irradiation: An American Society for Radiation Oncology (ASTRO) Evidence-Based Guideline. International Journal of Radiation Oncology*Biology*Physics. 2011 09;81(1):59-68. https://doi.org/10.1016/j.ijrobp.2010.04.042

8. Hall E. Radiobiogy for the radiologist. Walters Kluwer Health/ Lippincott Williams ans Wilkins; 2012.:35-50.

9. McLaughlin SA, Wright MJ, Morris KT, Sampson MR, Brockway JP, Hurley KE, Riedel ER, Van Zee KJ. Prevalence of Lymphedema in Women With Breast Cancer 5 Years After Sentinel Lymph Node Biopsy or Axillary Dissection: Patient Perceptions and Precautionary Behaviors. Journal of Clinical Oncology. 2008 Nov 10;26(32):5220-5226. https:// doi.org/10.1200/jco.2008.16.3766

10. Shah C, Wilkinson JB, Baschnagel A, Ghilezan M, Riutta J, Dekhne N, Balaraman S, Mitchell C, Wallace M, Vicini F. Factors Associated With the Development of Breast Cancer-Related Lymphedema After WholeBreast Irradiation. International Journal of Radiation Oncology*Biology*Physics. 2012 07;83(4):10951100. https://doi.org/10.1016/j.ijrobp.2011.09.058

11. Ugur S, Arıc1 C, Yaprak M, Mesc1 A, Arıcı GA, Dolay K, Ozmen V. Risk Factors of Breast Cancer-Related Lymphedema. Lymphatic Research and Biology. 2013 06;11(2):72-75. https://doi.org/10.1089/lrb.2013.0004

12. Jung S, Shin KH, Kim M, Chung SH, Lee S, Kang H, Lee ES, Kwon Y, Lee KS, Park IH, Ro J. Treatment factors affecting breast cancer-related lymphedema after systemic chemotherapy and radiotherapy in stage II/III breast cancer patients. Breast Cancer Research and Treatment. 201409 25;148(1):91-98. https://doi. org/10.1007/s10549-014-3137-x

13. Chandra RA, Miller CL, Skolny MN, Warren LE, Horick N, Jammallo LS, Sadek BT, Shenouda MN, O’Toole J, Specht MC, Taghian AG. Radiation Therapy Risk Factors for Development of Lymphedema in Patients Treated With Regional Lymph Node Irradiation for Breast Cancer. International Journal of Radiation Oncology*Biology*Physics. 2015 03;91(4):760-764. https://doi.org/10.1016/j.ijrobp.2014.12.029

14. Badiyan SN, Shah C, Arthur D, Khan AJ, Freedman G, Poppe MM, Vicini FA. Hypofractionated regional nodal irradiation for breast cancer: Examining the data and potential for future studies. Radiotherapy and Oncology. 2014 01;110(1):39-44. https://doi. org/10.1016/j.radonc.2013.12.006

15. Yarnold J, Bentzen SM, Coles C, Haviland J. Hypofractionated Whole-Breast Radiotherapy for Women With Early Breast Cancer: Myths and Realities. International Journal of Radiation Oncology*Biology*Physics. 2011 01;79(1):1-9. https://doi.org/10.1016/j.ijrobp.2010.08.035

16. Haffty BG, Buchholz TA. Hypofractionated breast radiation: preferred standard of care?. The Lancet Oncology. 2013 Oct;14(11):1032-1034. https://doi. 
org/10.1016/s1470-2045(13)70405-4

17. Schultheiss TE. The Radiation Dose-Response of the Human Spinal Cord. International Journal of Radiation Oncology*Biology*Physics. 2008 08;71(5):14551459. https://doi.org/10.1016/j.ijrobp.2007.11.075

18. Lundstedt D, Gustafsson M, Steineck G, Alsadius D, Sundberg A, Wilderäng U, Holmberg E, Johansson K, Karlsson P. Long-term symptoms after radiotherapy of supraclavicular lymph nodes in breast cancer patients. Radiotherapy and Oncology. 2012 05;103(2):155-160. https://doi.org/10.1016/j.radonc.2011.12.017

19. Bourgier C, Pessoa EL, Dunant A, Heymann S, Spielmann M, Uzan C, Mathieu M, Arriagada R, Marsiglia H. Exclusive Alternating Chemotherapy and Radiotherapy in Nonmetastatic Inflammatory Breast Cancer: 20 Years of Follow-Up. International Journal of Radiation Oncology*Biology*Physics. 2012 02;82(2):690-695. https://doi.org/10.1016/j. ijrobp.2010.11.040

20. Olsen NK, Pfeiffer P, Johannsen L, Schrøder H, Rose C. Radiation-induced brachial plexopathy: Neurological follow-up in 161 recurrence-free breast cancer patients. International Journal of Radiation Oncology*Biology*Physics. 1993 04;26(1):43-49. https://doi.org/10.1016/0360-3016(93)90171-q

21. Delanian S, Lefaix J, Pradat P. Radiation-induced neuropathy in cancer survivors. Radiotherapy and Oncology. 2012 Dec;105(3):273-282. https://doi. org/10.1016/j.radonc.2012.10.012

22. Hopwood P, Haviland JS, Sumo G, Mills J, Bliss JM, Yarnold JR. Comparison of patient-reported breast, arm, and shoulder symptoms and body image after radiotherapy for early breast cancer: 5-year followup in the randomised Standardisation of Breast Radiotherapy (START) trials. The Lancet Oncology. 2010 03;11(3):231-240. https://doi.org/10.1016/ s1470-2045(09)70382-1

23. Pinitpatcharalert A, Chitapanarux I, Euathrongchit J, et al. A retrospective study comparing hypofractionated radiotherapy and conventional radiotherapy in postmastectomy breast cancer. J Med Assoc Thai. 2011;94:S94-S102.

24. Powell S, Cooke J, Parsons C. Radiation-induced brachial plexus injury: follow-up of two different fractionation schedules. Radiotherapy and Oncology. 1990 07;18(3):213-220. https://doi.org/10.1016/01678140(90)90057-4

25. Rawlings G, Arriagada R, Fontaine F, Bouhnik H, Mouriesse H, Sarrazin D. Radiation-induced brachial plexopathy: Institut Gustave Roussy experience. Bull Cancer. 1983;70:77-83.

26. Soto O. Radiation-induced conduction block: Resolution following anticoagulant therapy. Muscle \& Nerve. 2005;31(5):642-645. https://doi.org/10.1002/ mus. 20273

27. Galecki J, Hicer-Grzenkowicz J, Grudzien-Kowalska M, Michalska T, Zalucki W. Radiation-induced brachial plexopathy and hypofractionated regimens in adjuvant irradiation of patients with breast cancer-a review. Acta Oncologica. 2006 01;45(3):280-284. https://doi.org/10.1080/02841860500371907

28. Johansson S, Svensson H, Denekamp J. Dose response and latency for radiation-induced fibrosis, edema, and neuropathy in breast cancer patients. International Journal of Radiation Oncology*Biology*Physics. 2002 04;52(5):1207-1219. https://doi.org/10.1016/ s0360-3016(01)02743-2

29. Johansson S, Svensson H, Larsson L, Denekamp J. Brachial Plexopathy After Postoperative Radiotherapy of Breast Cancer Patients: A Long-Term Follow-up. Acta Oncologica. 2000 01;39(3):373-382. https://doi. org/10.1080/028418600750013140

\section{(i) 8}

This work is licensed under a Creative Commons AttributionNon Commercial 4.0 International License. 